\title{
Efeito das células do cumulus e cisteamina durante o cultivo de maturação in vitro de oócitos bovinos sobre a maturação nuclear e aquisição da competência para desenvolvimento embrionário
}

[Effects of cumulus cells and cysteamine during bovine oocyte in vitro maturation on meiosis progression and acquisition of developmental competence]

\author{
F.P. Gottardi ${ }^{1}$, L.S.S. Barretto ${ }^{2}$, F.S. Gonçalves ${ }^{2}$, S.H.V. Perri ${ }^{1}$, G.Z. Mingoti ${ }^{1 *}$ \\ ${ }^{1}$ Faculdade de Medicina Veterinária - UNESP - Araçatuba, SP \\ ${ }^{2}$ Faculdade de Ciências Agrárias e Veterinárias - UNESP - Jaboticabal, SP
}

\begin{abstract}
RESUMO
Complexos cumulus-oócito (COC), oócitos desnudos (DO) e DO cocultivados com células do cumulus em suspensão (DO+CC) foram maturados in vitro (MIV) na presença ou ausência de cisteamina $(50 \mu \mathrm{M})$. Observou-se efeito benéfico da cisteamina durante o cultivo de MIV, pois a maturação nuclear no grupo COC cisteamina foi maior do que a do COC controle $(\mathrm{P}<0,05)$. No grupo sem a adição de cisteamina, foi observado que a ausência de CC durante o cultivo de MIV prejudicou a maturação nuclear em DO, em relação ao COC $(\mathrm{P}<0,05)$, todavia a cisteamina restaurou a capacidade de progressão da meiose em $\mathrm{DO}$, tornando-os semelhantes aos COC $(\mathrm{P}>0,05)$. O acoplamento entre oócitos e CC durante MIV demonstrou ser essencial para aquisição da competência do oócito para suportar o desenvolvimento embrionário inicial, pois COC apresentaram maior porcentagem de blastocistos e eclosão quando comparados a DO e $\mathrm{DO}+\mathrm{CC}(\mathrm{P}<0,05)$. A inclusão de cisteamina no cultivo de MIV não restaurou a aquisição da competência em DO e DO+CC, que permaneceram semelhantes aos do grupo-controle $(\mathrm{P}>0,05)$. Conclui-se que a cisteamina no meio de MIV melhora as taxas de maturação nuclear em COC e restaura a capacidade de progressão da meiose em DO. Todavia, na concentração utilizada neste estudo, não promove efeito benéfico no desenvolvimento embrionário.
\end{abstract}

Palavras-chave: bovino, célula do cumulus, cisteamina, maturação in vitro, oócito

\begin{abstract}
Cumulus-oocyte complexes (COC), denuded oocytes (DO) and DO co-cultured with cumulus cells in suspension $(D O+C C)$ were in vitro matured $(I V M)$ in the presence or absence of cysteamine $(50 \mu M)$. A beneficial effect of cysteamine was observed during IVM, because the nuclear maturation in the COC cysteamine group was higher than in COC control $(P<0.05)$. In the control group, the absence of CC during IVM impaired nuclear maturation in DO when compared to COC $(P<0.05)$, but cysteamine restored the ability of meiosis progression in DO, making them similar to COC $(P>0.05)$. The coupling between oocytes and CC during IVM proved to be essential for the acquisition of oocyte competence to support early embryonic development, as COC had higher percentages of blastocyst and hatching when compared to DO and DO+DC $(P<0.05)$. However, the inclusion of cysteamine in the IVM culture did not restore the acquisition of competence in $D O$ and $D O+D C$, which remained similar to the control group $(P>0.05)$. It is concluded that cysteamine in the IVM culture improves the nuclear maturation in COC and restores the progression ability of meiosis in DO. However, in the concentration used in this study, cysteamine does not promote a beneficial effect on embryo development.
\end{abstract}

Keywords: cattle, cumulus cells, cysteamine, in vitro maturation, oocyte

Recebido em 20 de fevereiro de 2011

Aceito em 29 de dezembro de 2011

*Autor para correspondência (corresponding author)

E-mail: gmingoti@fmva.unesp.br 


\section{INTRODUÇÃO}

Oócitos de mamíferos e suas células da granulosa intimamente associadas, denominadas células do cumulus, são interconectados por uma rede extensiva de canais transmembrana conhecidos como gap junctions (Loewenstein, 1987). Estas células exercem um papel crucial durante o crescimento e desenvolvimento do oócito incluso no folículo e, posteriormente, durante sua maturação e fertilização (Tanghe et al., 2003). As gap junctions atuam no suporte metabólico do oócito, uma vez que permitem a transferência bidirecional de moléculas de baixo peso molecular, íons e aminoácidos, os quais atuam como nutrientes e mensageiros (Loewenstein, 1987). Alguns desses mensageiros são responsáveis pela manutenção do bloqueio meiótico (Albertini et al., 2001), sendo que o 3'5 ' monofosfato de adenosina cíclico (AMPc) é o principal mensageiro envolvido na manutenção do oócito imaturo em estádio de vesícula germinativa $(\mathrm{VG})$ e na indução da retomada da meiose (Lastro et al., 2006).

Adicionalmente, existem evidências de que fatores secretados pelas células do cumulus são também importantes para a promoção da maturação citoplasmática do oócito (Tanghe et al., 2003) e a aquisição da competência para o desenvolvimento embrionário (Hashimoto e Kishimoto, 1998; Gilchrist et al., 2008), sendo que esses parâmetros podem ser avaliados pela determinação da taxa de desenvolvimento embrionário após a fecundação. Todavia, a remoção das células do cumulus durante momentos específicos do cultivo de maturação é necessária para realização de algumas biotécnicas, como, por exemplo, a clonagem por transferência de núcleo de células somáticas e a criopreservação de oócitos em fase de VG. Um sistema de cultivo eficiente para maturação in vitro (MIV) de oócitos desnudos poderia melhorar a eficácia de tais biotécnicas, bem como responder algumas questões sobre o efeito das células do cumulus sobre a maturação do oócito (Zhou et al., 2008).

Glutationa (GSH) é um antioxidante natural presente em ambos os gametas e tem papel importante na proteção contra os efeitos prejudiciais das espécies reativas de oxigênio (ROS) e na regulação da síntese de proteínas e DNA pela alteração do status de redução- oxidação (De Matos e Furnus, 2000). O aumento na concentração intracelular de GSH é mostrado em oócitos que progridem da fase de VG para metáfase II (MII) (Funahashi et al., 1995) e, devido a isso, os níveis intracelulares de GSH oocitário no final da maturação são considerados bons marcadores bioquímicos da viabilidade do oócito (Abeydeera et al., 1998).

A síntese de GSH é altamente dependente da disponibilidade de cisteína no meio de cultivo (De Matos et al., 1997). O meio TCM199, o qual é mais frequentemente utilizado para o cultivo de oócitos bovinos, é enriquecido com cistina e cisteína, $0,108 \mathrm{mM}$ e $0,000568 \mathrm{mM}$, respectivamente (Technical..., 2009). Todavia, essencialmente, nenhuma cisteína é encontrada no meio, devido ao fato de esta ser instável fora da célula e ser auto-oxidada à cistina (De Matos et al., 1997). Em células somáticas, a cisteamina pode reduzir cistina à cisteína, promovendo melhor captação da cisteína e aumento na síntese de GSH (Issels et al., 1988). De fato, já foi previamente demonstrado que a adição de cisteamina ao meio de MIV melhora a maturação oocitária e o desenvolvimento embrionário devido à elevação do conteúdo de GSH em complexos cumulus-oócito (De Matos et al., 1995; Abeydeera et al., 1998; De Matos et al., 2002). Dessa forma, a adição de antioxidantes ao meio de MIV, tais como cisteamina, cisteína e 2mercaptoetanol, aumenta a síntese de GSH no oócito bovino (De Matos et al., 1997), suprindo-o com um grande estoque de GSH disponível para proteção do embrião até o estádio de blastocisto (De Matos et al., 1995).

O objetivo deste estudo foi avaliar o efeito da adição de cisteamina ao meio de maturação in vitro de complexos cumulus-oócito (COC), oócitos desnudos (DO) e oócitos desnudos cocultivados com células do cumulus dispersas (DO+CC) sobre a maturação nuclear e aquisição da competência de desenvolvimento embrionário.

\section{MATERIAL E MÉTODOS}

Ovários foram obtidos de matadouro e transportados para o laboratório em solução salina a $30-35^{\circ} \mathrm{C}$. Folículos de 2 a $8 \mathrm{~mm}$ foram aspirados com auxílio de agulha de calibre $18 \mathrm{G}$ acoplada à seringa de $20 \mathrm{~mL}$. Oócitos com citoplasma homogêneo e com pelo menos quatro 
camadas de células do cumulus foram selecionados para o experimento.

Os oócitos selecionados foram lavados e subdivididos em três tipos distintos: 1) oócitos intactos (COC); 2) oócitos desnudos (DO), obtidos após remoção mecânica das células do cumulus por agitação em vortex (3min), depois do processo de seleção; 3) DO, obtidos como descrito anteriormente e cultivados na presença das suas próprias células do cumulus dispersas no meio de maturação (DO+CC).

O meio de maturação foi constituído de TCM199 (Gibco BRL, Grand Island, NY, USA) suplementado com $0,6 \%$ de albumina bovina sérica (BSA; Sigma Chemical Co., St. Louis, MO, USA), 0,2mM de piruvato de sódio (Sigma), 25mM de bicarbonato de sódio (Sigma), $75 \mu \mathrm{g} / \mathrm{mL}$ de gentamicina (Gibco), $0,5 \mu \mathrm{g} / \mathrm{mL}$ de FSH (Pluset ${ }^{\circledR}$, Calier), $100 \mathrm{UI} / \mathrm{mL}$ hCG (Profasi ${ }^{\circledR}$, Serono, São Paulo, Brasil) e $1,0 \mu \mathrm{g} / \mathrm{mL}$ de estradiol (Sigma). A maturação foi realizada em gotas de $100 \mu \mathrm{L}$ de meio de maturação sem (grupo-controle) ou com adição de $50 \mu \mathrm{M}$ de cisteamina (Sigma; grupo cisteamina), sob óleo mineral (Dow Corning Co, Midland, MI, USA), temperatura de $38,5^{\circ} \mathrm{C}$, máxima umidade e atmosfera de $5 \% \mathrm{CO}_{2} \mathrm{em}$ ar, durante 24 horas. Para cada grupo, foram maturados, aproximadamente, 20 oócitos por gota, em cinco repetições realizadas em dias distintos.

Ao final do cultivo de maturação, um grupo de oócitos ( $n=555$, em cinco repetições) foi corado com $10 \mu \mathrm{g} / \mathrm{mL}$ Hoechst 33342, e estes foram visualizados sob microscópico de epifluorescência (330-385nm; aumento de 200X) para determinação dos estádios da meiose. Aqueles que possuíam uma placa metafásica e o primeiro corpúsculo polar foram classificados em estádio de MII e considerados maturados. Oócitos que se encontravam em outros estádios da meiose, como VG, quebra da VG, metáfase I, anáfase I e telófase I, foram considerados imaturos.

Os demais oócitos ( $n=558$, em cinco repetições) foram submetidos à fecundação in vitro (FIV). Para tanto, uma palheta de sêmen de um único touro da raça Nelore foi descongelada $\left(37^{\circ} \mathrm{C}\right.$ por 30s) e os espermatozoides viáveis foram obtidos por centrifugação $(900 \times$ g) em gradiente descontínuo de densidade de Percoll (Pharmacia, Uppsala, Suécia; $2 \mathrm{~mL}$ de $45 \%$ Percoll mais $2 \mathrm{~mL}$ de Percoll 90\%) em temperatura ambiente. Os espermatozoides foram adicionados às gotas de FIV em uma concentração final de $2 \times 10^{6}$ células $/ \mathrm{mL}$. O meio de FIV foi o Tyrode's-albumina-lactato-piruvato (TALP) suplementado com 0,2mM Na-piruvato, $6 \mathrm{mg} / \mathrm{mL}$ BSA livre de ácido graxo, $25 \mathrm{mM}$ de bicarbonato de sódio, 13mM Na-lactato (Sigma), $75 \mu \mathrm{g} / \mathrm{mL}$ de gentamicina, $4 \mu 1 / \mathrm{mL}$ de solução de PHE (1 $\mathrm{mM}$ de hipotaurina, $2 \mathrm{mM}$ de penicilamina e $250 \mu \mathrm{M}$ epinefrina; Sigma) e $10 \mu \mathrm{g} / \mathrm{mL}$ de heparina (Sigma). Oócitos e espermatozoides foram coincubados por $18 \mathrm{~h}$ sob as mesmas condições descritas para o cultivo de MIV.

Ao término do cultivo de FIV, os prováveis zigotos foram lavados e transferidos para o cultivo in vitro (CIV), realizado sob as mesmas condições descritas para os cultivos anteriores, em $100 \mu \mathrm{L}$ de meio sintético de fluido de oviduto (SOF) suplementado com $0,2 \mathrm{mM}$ de L-glutamina (Sigma), 0,34mM de citrato de sódio (Merck), 2,8mM de myo-inositol (Sigma), $2 \%$ de solução de aminoácidos essenciais (MEM; Sigma), 1\% de aminoácidos não essenciais (MEM; Sigma), $0,2 \mathrm{mM}$ de piruvato de sódio, $75 \mu \mathrm{g} / \mathrm{mL}$ de gentamicina, $5 \mathrm{mg} / \mathrm{mL}$ BSA livre de ácido graxo fração $\mathrm{V}$ e $2,5 \%$ de soro fetal bovino (SFB). A taxa de clivagem foi avaliada 48 horas após a inseminação (HPI), sob microscópio estereoscópico (aumento 40X), quando embriões de duas e quatro células foram contados. As taxas de desenvolvimento embrionário até as fases de blastocisto e eclosão de blastocistos foram observadas, respectivamente, às 168 (dia 7) e 216 (dia 9) HPI.

As taxas de oócitos que completaram a meiose (atingiram o estádio de MII) foram calculadas em função do total de oócitos cultivados em MIV. As taxas de produção de blastocistos no sétimo dia de cultivo e de blastocistos eclodidos no nono dia foram calculadas em função do total de oócitos inseminados. Os resultados referentes aos seis grupos avaliados neste estudo foram analisados pelo teste do qui-quadrado. Considerou-se significante o nível de $\mathrm{P}<0,05$. 


\section{RESULTADOS}

Tanto para a avaliação da maturação nuclear quanto para clivagem e desenvolvimento embrionário, os seis grupos testados neste trabalho foram comparados entre si e os resultados são mostrados, respectivamente, na Fig. 1 e na Tab. 1. Todavia, para facilitar a compreensão dos resultados, serão destacadas apenas as análises relevantes, ou seja, comparação entre os tipos de oócitos dentro de grupo (controle ou cisteamina), e comparação entre os grupos dentro de tipo de oócito (COC, $\mathrm{DO}$ ou DO+CC).
A comparação entre os diferentes tipos de oócitos cultivados em meio controle (Fig. 1; sem adição de cisteamina) demonstrou que as maiores taxas de MII foram atingidas pelos $\mathrm{COC}$ e as menores pelos DO $(\mathrm{P}<0,05)$; com relação aos $\mathrm{DO}+\mathrm{CC}$, as taxas de MII foram semelhantes $(\mathrm{P}>0,05)$ às dos COC e DO. A comparação entre os diferentes tipos de oócitos cultivados na presença de cisteamina demonstrou maiores taxas de MII para COC e menores para DO+CC $(\mathrm{P}<0,05)$, sendo que para DO as taxas de MII foram semelhantes às destes grupos $(\mathrm{P}>0,05)$.

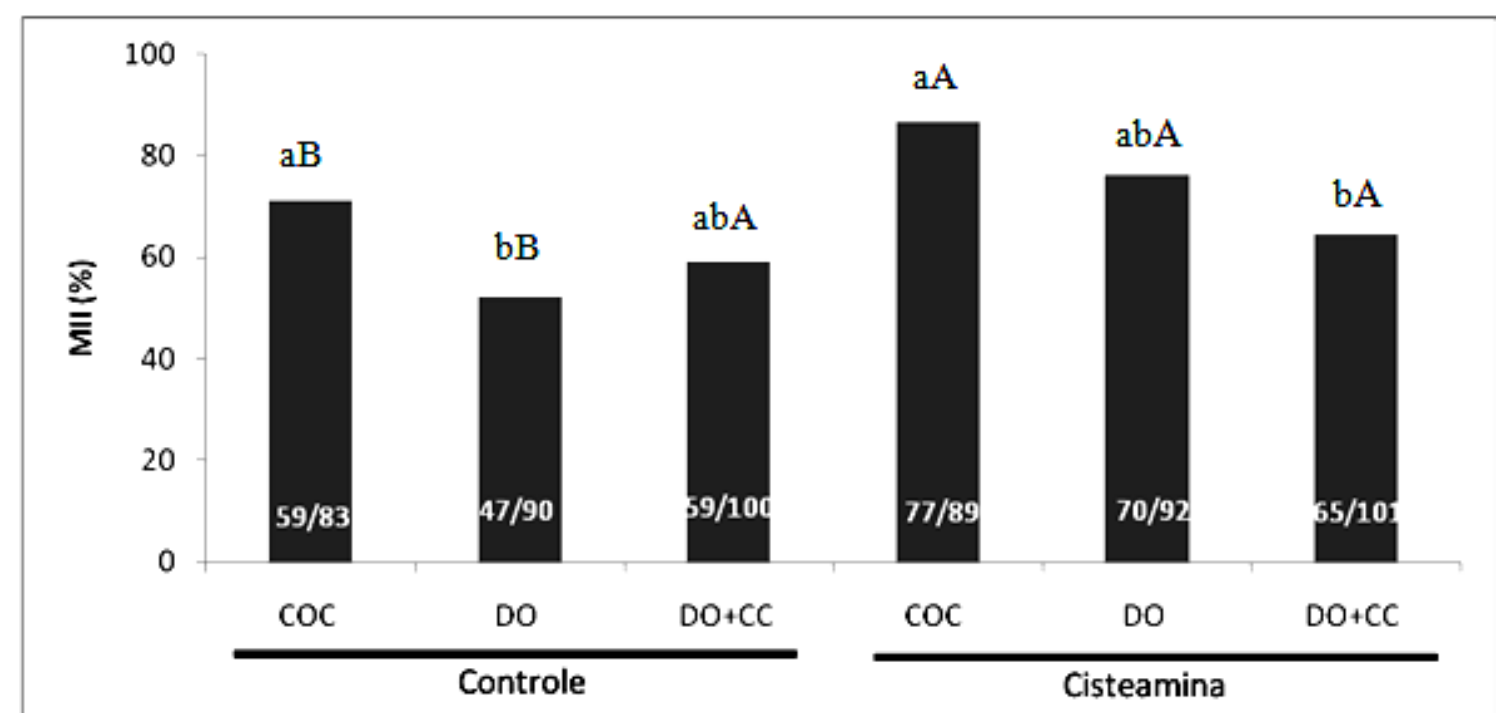

Figura 1. Porcentagem (\%) de oócitos que atingiram a fase de metáfase II (MII) da meiose, segundo o tipo de oócito (COC, DO e DO+CC) e o grupo (controle e cisteamina).

Letras minúsculas nas colunas comparam tipo de oócito (COC, DO, DO + CC) dentro de grupo (com ou sem cisteamina). Letras maiúsculas nas colunas comparam grupos (com e sem cisteamina) dentro do tipo de oócito. Colunas com letras distintas (maiúsculas ou minúsculas) indicam diferenças na taxa de MII (teste do qui-quadrado; P<0,05). COC: complexo cumulus-oócito; DO: oócito desnudo; DO + CC: oócitos desnudos cocultivados com células do cumulus dispersas.

Ainda, quanto à maturação nuclear, ao se comparar os grupos controle e cisteamina, para cada tipo de oócito, observaram-se taxas de MII mais altas no grupo cisteamina do que no grupo-controle $(\mathrm{P}<0,05)$ para os COC e DO. Com relação aos $\mathrm{DO}+\mathrm{CC}$, não foi observada diferença entre os grupos $(\mathrm{P}>0,05)$.

As maiores taxas de clivagem foram obtidas nos COC dos grupos controle e cisteamina, as quais foram mais altas $(\mathrm{P}<0,05)$ que as dos grupos $\mathrm{DO}$ controle, DO+CC controle, DO cisteamina e
$\mathrm{DO}+\mathrm{CC}$ cisteamina. Tanto no grupo controle como no cisteamina, a taxa de clivagem foi semelhante $(\mathrm{P}>0,05)$ entre $\mathrm{DO}$ e DO+CC (Tab. 1).

A comparação entre os grupos controle e cisteamina, para cada tipo de oócito cultivado, não demonstrou diferença na taxa de clivagem $(\mathrm{P}>0,05)$ para $\mathrm{COC}$ e $\mathrm{DO}+\mathrm{CC}$, todavia observou-se menor taxa de clivagem $(\mathrm{P}<0,05)$ no grupo DO cisteamina do que no grupo DO controle. 
Tabela 1. Número (n) e porcentagem (\%) de oócitos clivados, embriões desenvolvidos até o estágio de blastocisto (168HPI) e eclosão de blastocistos (216HPI) em relação ao total de oócitos inseminados, segundo o tipo e o grupo em cada fase do desenvolvimento embrionário

\begin{tabular}{|c|c|c|c|c|c|}
\hline \multirow[t]{2}{*}{ Grupo } & \multirow[t]{2}{*}{ Tipo de oócito } & \multirow[t]{2}{*}{$\begin{array}{l}\text { Oócitos } \\
\text { (Total) }\end{array}$} & \multicolumn{3}{|c|}{$\begin{array}{c}\text { Desenvolvimento embrionário } \\
\mathrm{n}(\%)\end{array}$} \\
\hline & & & Clivagem & Blastocisto & Eclosão \\
\hline \multirow[t]{3}{*}{ Controle } & $\mathrm{COC}$ & 99 & $90(90,9) \mathrm{aA}$ & $33(33,3) \mathrm{aA}$ & $21(21,1) \mathrm{aA}$ \\
\hline & DO & 97 & $60(61,9) \mathrm{bA}$ & $11(11,3) \mathrm{bA}$ & $2(2,1) \mathrm{bA}$ \\
\hline & $\mathrm{DO}+\mathrm{CC}$ & 84 & $56(66,7) \mathrm{bA}$ & $9(10,7) \mathrm{bA}$ & $5(6,0) \mathrm{bA}$ \\
\hline \multirow[t]{3}{*}{ Cisteamina } & $\mathrm{COC}$ & 95 & $86(90,5) \mathrm{aA}$ & $35(36,8) \mathrm{aA}$ & $20(21,1) \mathrm{aA}$ \\
\hline & $\mathrm{DO}$ & 94 & $44(46,8) b B$ & $7(7,4) \mathrm{bA}$ & $0(0,0) \mathrm{bA}$ \\
\hline & $\mathrm{DO}+\mathrm{CC}$ & 92 & $55(59,8) \mathrm{bA}$ & $8(8,7) \mathrm{bA}$ & $4(4,4) \mathrm{bA}$ \\
\hline
\end{tabular}

Letras minúsculas nas colunas comparam tipo de oócito (COC, DO, DO + CC) dentro de grupo (com ou sem cisteamina). Letras maiúsculas nas colunas comparam grupos (com e sem cisteamina) dentro do tipo de oócito. Colunas com letras distintas (maiúsculas ou minúsculas) indicam diferenças nas taxas de clivagem, blastocisto e eclosão (teste do qui-quadrado: $\mathrm{P}<0,05$ ). COC: complexo cumulus-oócito; DO: oócito desnudo; DO + CC: oócitos desnudos cocultivados com células do cumulus dispersas.

As taxas de embriões desenvolvidos até o estádio de blastocisto (168 HPI), bem como as taxas de eclosão de blastocistos (216 HPI), foram mais elevadas $(\mathrm{P}<0,05)$ para COC controle e COC cisteamina, quando comparados com os demais grupos (DO controle, $\mathrm{DO}+\mathrm{CC}$ controle, $\mathrm{DO}$ cisteamina e $\mathrm{DO}+\mathrm{CC}$ cisteamina). Com relação a estes últimos, as taxas foram semelhantes $(\mathrm{P}>0,05)$ entre si.

Para cada tipo de oócito, as taxas de blastocistos e eclosão foram semelhantes $(\mathrm{P}>0,05)$ entre os grupos controle e cisteamina.

\section{DISCUSSÃO}

O processo de maturação compreende todos os eventos que permitem ao oócito expressar seu potencial máximo de desenvolvimento após a fecundação. A maturação nuclear é iniciada com a retomada da meiose (GVBD), passa pela fase de metáfase I, conclusão da primeira redução meiótica, emissão do primeiro corpúsculo polar e, finalmente, atinge a fase de metáfase II. Estes passos, juntamente com a maturação citoplasmática, preparam o oócito para a fecundação e aquisição da competência para o desenvolvimento embrionário (Sirard et al., 1989). O oócito e suas células foliculares adjacentes (células do cumulus), bem como as condições do sistema de cultivo e a composição do meio de MIV, exercem influência no subsequente desenvolvimento embrionário (De Matos et al., 1997; Hashimoto e Kishimoto, 1998; Gilchrist et al., 2008).

Já foi demonstrado que a adição de cisteamina ao meio de MIV melhora a maturação citoplasmática, mais especificamente a maturação bioquímica e molecular, por promover a elevação do conteúdo de GSH (De Matos et al., 1995; Abeydeera et al., 1998; De Matos et al., 2002). Todavia, no presente estudo, observou-se também efeito positivo da adição de cisteamina ao meio de MIV sobre a taxa de oócitos que concluíram a maturação nuclear quando estes foram cultivados inclusos nas células do cumulus ou desnudos destas células.

Durante a MIV, oócitos são frequentemente cultivados na presença das células do cumulus e sabe-se que a maturação e a aquisição da competência para o desenvolvimento embrionário adquiridas pelo oócito durante a MIV são processos dependentes do acoplamento metabólico entre oócito e células do cumulus, através do qual existe a passagem de diversos metabólitos que atuam no desenvolvimento do oócito (Loewenstein, 1987) e na progressão da maturação nuclear (Albertini et al., 2001; Lastro et al., 2006). No presente trabalho, como esperado, observou-se que a presença das células 
do cumulus é também importante para dar suporte à progressão da meiose, uma vez que foram observadas menores taxas de MII em DO em comparação com COC, ambos do grupocontrole. Entretanto, quando DO foram cocultivados na presença de cisteamina, as taxas de MII foram semelhantes às dos COC. Resultados semelhantes foram descritos por Zhou et al. (2008), ao avaliarem oócitos desnudos de cabras. A promoção de melhores taxas de MII após cultivo de DO em meio suplementado com cisteamina pode ser atribuída ao possível efeito protetor do $\mathrm{GSH}$, conforme discutido anteriormente.

Oócitos cocultivados com células do cumulus dispersas $(\mathrm{DO}+\mathrm{CC})$ no meio de maturação resultaram em taxas de MII semelhantes às dos COC (grupo-controle), todavia, quando cultivados na presença de cisteamina, as taxas de MII dos DO+CC foram mais baixas que as dos COC. No presente estudo, houve desagregação entre as células do cumulus e oócitos, sendo que todos os contatos ou comunicação através desses contatos foram perdidos. Sabe-se que a ruptura da integridade da matriz extracelular e a inibição dos contatos intercelulares são fatores capazes de induzir a apoptose em vários tipos celulares (Bates et al., 1994). De fato, folículos em desenvolvimento possuem gap junctions que coordenam as respostas funcionais das células da granulosa entre si e destas com o oócito, enquanto o contato célula-a-célula através do complexo juncional é reduzido em folículos ovarianos atrésicos (Albertini et al., 2001). Mesmo in vitro, a ruptura da integridade dos contatos entre as células é capaz de promover a diminuição da proliferação celular e de estimular a apoptose, seja em células da granulosa murais ou em células do cumulus (Luciano et al., 2000). Dessa forma, pressupõe-se que tenha ocorrido um provável índice elevado de apoptose pelas células do cumulus desagregadas. Os dados deste estudo demonstram que o ambiente proporcionado pelo cocultivo de $\mathrm{DO}+\mathrm{CC}$ não foi prejudicial à progressão da meiose até a fase de MII, todavia, de alguma maneira, não permitiu que a cisteamina melhorasse esses índices quando presente no cultivo. Parece provável que algum mecanismo desconhecido, relativo à fisiologia ou ao metabolismo das células em cocultivo com o oócito, possa ter mascarado ou alterado os mecanismos que poderiam ter levado a melhores taxas de maturação, como ocorreu no caso dos COC e DO na presença de cisteamina.

Com relação ao desenvolvimento embrionário, observou-se que a integridade do complexo formado pelo oócito e suas respectivas células do cumulus durante a MIV foi essencial para a aquisição da competência oocitária, uma vez que as taxas de clivagem, de desenvolvimento embrionário até a fase de blastocisto e de eclosão foram mais altas para o grupo COC, independentemente de terem sido maturados na presença ou ausência de cisteamina. Estes resultados estão de acordo com estudos anteriores, os quais demonstraram que a interconexão entre células do cumulus e oócito é crítica para a obtenção da competência para o desenvolvimento (De Mattos et al., 1997; Luciano et al., 2000; Senbon et al., 2003; Luciano et al., 2005). Mesmo na fecundação, as células do cumulus parecem ser importantes, pois atuam na atração e seleção de espermatozoides, facilitam a capacitação espermática, a reação acrossomal, a penetração, e previnem o endurecimento precoce da zona pelúcida (Thanghe et al., 2003). Provavelmente, a secreção de produtos metabólicos do cumulus ao redor do oócito cria um microambiente complexo que é benéfico ao processo de fecundação. Dessa forma, os dados confirmam que a integridade das células do cumulus adjacentes ao oócito deve proporcionar melhor aquisição da competência oocitária durante a MIV, o que resulta em melhores taxas de fecundação e desenvolvimento embrionário.

Luciano et al. (2005) demonstraram que a restauração completa da plena competência de DO só pode ser obtida quando estes são cocultivados com COC durante a maturação e a fecundação, mas não quando cocultivados com células da granulosa ou do cumulus dispersas. Esses autores demonstraram que a interação entre oócitos versus células do cumulus não é essencial durante a MIV e FIV de DO, todavia sugerem que possíveis fatores produzidos pelas células do cumulus, e/ou pela interação entre essas células e oócito, quando interconectados na forma de COC, sejam difundidos para o meio e, assim, possam atuar melhorando a capacidade de DO.

Foi discutido anteriormente que a adição de antioxidantes, como cisteamina, $\beta$ - 
mercaptoetanol, cisteína ou cistina ao meio de MIV, melhora a aquisição da competência oocitária, resultando em maiores taxas de desenvolvimento e qualidade embrionária (De Matos et al., 1995; De Matos e Furnus, 2000; De Matos et al., 2002). No presente estudo, entretanto, a adição de cisteamina durante o cultivo de MIV de COC, DO e DO+CC não alterou as taxas de desenvolvimento embrionário e de eclosão de blastocistos. Neste estudo, a cisteamina foi adicionada apenas durante $o$ cultivo de maturação, mas não em etapas posteriores durante cultivo embrionário in vitro (CIV). Em estudo anterior, De Matos et al. (2002) observaram melhores taxas de desenvolvimento embrionário quando oócitos foram maturados na presença de cisteamina, todavia a inclusão deste antioxidante durante a MIV e CIV melhorou ainda mais o desenvolvimento embrionário. Segundo esses autores, a elevação na concentração intracelular de oócitos promovida pela cisteamina durante a MIV tem papel crucial na proteção dos embriões contra os danos causados pelo estresse oxidativo. Os danos causados pela geração de espécies reativas de oxigênio são ainda mais significativos quando os embriões são cultivados em incubadora com elevada tensão de oxigênio (5\% $\mathrm{CO}_{2}$ em ar atmosférico), como foi o caso no presente estudo. Pode-se supor, portanto, que um possível estresse oxidativo durante o cultivo embrionário tenha esgotado o estoque de GSH produzido durante a MIV (Luciano et al., 2005). Dessa forma, a inclusão de antioxidantes durante o CIV parece ser essencial para que o efeito benéfico seja estendido a esta etapa adicional da produção in vitro de embriões bovinos.

Outro fato que deve ser levado em consideração é a dose de cisteamina utilizada no cultivo de oócitos ou embriões. De Matos et al. (2002) avaliaram a dose efetiva de cisteamina durante a MIV e observaram maiores taxas de blastocistos após suplementação do meio de maturação com 50,100 e $200 \mu \mathrm{M}$ de cisteamina, sugerindo que, mesmo a concentração mais baixa $(50 \mu \mathrm{M})$ de cisteamina, semelhante à que foi utilizada neste trabalho, é benéfica para proporcionar melhores taxas de produção de blastocistos. No entanto, de acordo com esses autores, a dose de $100 \mu \mathrm{M}$ pode aumentar ainda mais a produção de blastocistos. Dessa forma, pode-se supor que a concentração de $50 \mu \mathrm{M}$ de cisteamina adicionada ao meio de MIV foi capaz de proporcionar aumento da concentração de GSH do oócito de forma suficiente para melhorar a maturação nuclear, contudo não possibilitou a melhora das taxas de desenvolvimento embrionário. Hipotetiza-se que a quantidade de GSH sintetizado durante a MIV pode ter sido totalmente consumida durante o processo de maturação e fertilização, não tendo sido capaz de proporcionar melhores taxas de desenvolvimento embrionário posterior.

No presente estudo, as taxas de desenvolvimento embrionário até blastocisto para o grupo COC controle foram $35,5 \%, 43,5 \%$ e $44,5 \%$, respectivamente, para os dias sete, oito e nove de cultivo. Esses valores são mais altos que os observados na literatura. De Matos et al. (1995; 2000) e Balassubramanian et al. (2007) obtiverem média de $20 \%$ de blastocistos no dia sete e demonstraram melhora no desenvolvimento embrionário de oócitos maturados in vitro com suplementação de cisteamina. Similarmente aos resultados do presente estudo, Luciano et al. (2005) obtiveram no dia sete média de $38 \%$ de blastocistos de oócitos maturados na presença de cisteamina e nenhum efeito desse antioxidante sobre o desenvolvimento embrionário. Portanto, estudos que utilizam cisteamina no meio de MIV apresentam resultados contraditórios, e, provavelmente, essas diferenças sejam devido também a outros fatores desconhecidos, relacionados aos diferentes sistemas de cultivos usados nos vários estudos.

\section{CONCLUSÕES}

A ausência de células do cumulus durante o cultivo de maturação de oócitos bovinos prejudica a maturação nuclear, todavia a suplementação de cisteamina no meio de MIV restaura a capacidade de progressão da meiose em oócitos desnudos. Além disso, o acoplamento metabólico entre oócitos e células do cumulus durante a MIV é essencial para aquisição da competência do oócito para suportar o subsequente desenvolvimento embrionário inicial. A inclusão de $50 \mu \mathrm{M}$ de cisteamina no cultivo de MIV promove melhores taxas de maturação nuclear em complexos cumulus-oócito e em oócitos desnudos, mas não em oócitos cocultivados com células do cumulus dispersas no meio de cultivo. Contudo, nessa concentração, não promove efeito benéfico no desenvolvimento embrionário. 


\section{AGRADECIMENTOS}

À Fundação de Amparo a Pesquisa do Estado de São Paulo (FAPESP), pela bolsa de estudo concedida durante a realização do trabalho, e à Fundação para o Desenvolvimento da UNESP (FUNDUNESP).

\section{REFERÊNCIAS}

ABEYDEERA, L.R.; WANG, W.H.; CANTLY, T.C. et al. Presence of B-mercaptoethanol can increase the glutathione content of pig oocytes matured in vitro and the rate of blastocyst development after in vitro fertilization. Theriogenology, v.50, p.747-756, 1998.

ALBERTINI, D.F.; COMBELLES, C.M.; BENECCHI, E. et al. Cellular basis for paracrine regulation of ovarian follicle development. Reproduction, v.121, p.647-653, 2001.

BATES R.C.; BURET A.; VAN HELDEN D.F. et al. Apoptosis induced by inhibition of intercellular contact. J. Cell Biol., v.125, p.403-415, 1994.

BALASUBRAMANIAN, S.; RHO, G-J. Effect of cysteamine supplementation of in vitro matured bovine oocytes on chilling sensitivity and development of embryos. Anim. Reprod. Sci., v.98, p.282-292, 2007.

DE MATOS, D.G.; FURNUS, C.C.; MOSES, D.F. et al. Effect of cysteamine on glutathione level and developmental capacity of bovine oocyte maturede in vitro. Mol. Reprod. Dev., v.42, p.432-436, 1995.

DE MATOS, D.G.; FURNUS, C.C.; MOSES, D.F. Glutathione synthesis in vitro maturation of bovine oocytes: role of cumulus cells. Biol. Reprod., v.57, p.1420-1425, 1997.

DE MATOS, D.G.; FURNUS, C.C. The importance of having high glutathione (GSH) level after bovine in vitro maturation on embryo development effect of beta-mercaptoethanol, cysteine and cystine. Theriogenology, v.53, p.761-771, 2000.

DE MATOS, D.G.; GASPARRINI, B; PASQUALINI, S.R. et al. Effect of glutathione synthesis stimulation during in vitro maturation of ovine oocytes on embryo development and intracellular peroxide content. Theriogenology, v.57, p.1443-1451, 2002.

FUNAHASHI, H.; STUMPF, T.T.; CANTELY, T.C. et al. Pronuclear formation and intracellular glutathione content of in vitro matured porcine oocytes following in vitro fertilization and/or electrical activation. Zigote, v.3, p.273-281, 1995.

GILCHRIST, R.B.; LANE, M.; THOMPSON, J.G. Oocyte-secreted factors: regulators of cumulus cell function and oocyte quality. Human Reprod. Update, v.14, p.159-177, 2008.
HASHIMOTO, H.; KISHIMOTO, T. Regulation of meiotic maturation by a cytoplasmic maturationpromoting factor during mouse oocyte maturation. Dev. Biol., v.126, p.242-252, 1998.

ISSELS, R.D.; NAGELE, A.; ECKERT, K.G. et al. Promotion of cystine uptake and its utilization for glutathione biosynthesis induced by cysteamine and N-acetylcysteine. Biochem. Pharmacol., v.37, p.881$888,1988$.

LASTRO, M.; COLLINS, S.; CURRIE, W.B. Adenylyl cyclases in oocyte maturation:a characterization of AC isoforms in bovine cumulus cells. Mol. Reprod. Dev., v.73, p.1202-1210, 2006.

LOEWENSTEIN, W.R. The cell-to-cell channel of gap junctions. Cell, v.48, p.725-726, 1987.

LUCIANO, A.M.; MODINA, S.; GANDOLFI, F. et al. Effect of cell-to-cell contact on in vitro deoxyribonucleic acid synthesis and apoptosis responses of bovine granulosa cells to insulin-like growth factor-I and epidermal growth factor. Biol. Reprod., v.63, p.1580-1585, 2000.

LUCIANO, M.A.; LODDE, V.; BERETTA, M.S. et al. Developmental capability of denuded bovine oocyte in a co-culture system with intact cumulusoocyte complexes: role of cumulus cells,cyclic adenosine 3,5-monophosphate, and glutathione. Mol. Reprod. Dev., v.71, p.389-397, 2005.

SENBON, S.; HARAO Y.; MIYANO T. Interactions between the oocyte and sunrrounding somatic cells in folicular development: Lesssons from in vitro culture. J. Reprod. Dev., v.9, p.259-269, 2003.

SIRARD, M.A.; FLORMAN, H.M.; LEIBFRIEDRUTLEDGE, M.L. et al. Timing of nuclear progression and protein synthesis necessary for meiotic maturation of bovine oocytes. Biol. Reprod., v.40, p.1257-1263 1989.

TANGHE, S.; SOOM, A.V.; MEHRZAD, J. et al. Cumulus contributions during bovine fertilization in vitro. Theriogenology, v.60, p.135-149, 2003.

TECHNICAL RESOURCES, Media Formulations, Medium 199 powder, 2009. Disponível em:<http://www.invitrogen.com/site/us/en/home/supp ort/Product-Technical-

Resources/mediaformulation.90.html>. Acessado em: 16 set. 2009.

ZHOU, P.; WU, Y-G.; LI, Q. et al. The interactions between cysteamine, cystine and cumulus cells increase the intracellular glutathione level and developmental capacity of goat cumulus-denuded oocytes. Reproduction, v.135, p.605-611, 2008. 